\title{
Antropologia e pandemia: escalas e conceitos
}

\section{Anthropology and pandemic: scales and concepts}

\author{
Taniele Rui' \\ https://orcid.org/0000-0002-2404-3959 \\ tanielerui@gmail.com \\ Isadora Lins França' \\ https://orcid.org/0000-0001-9884-1059 \\ isalinsf@gmail.com \\ Bernardo Fonseca Machado" \\ https://orcid.org/0000-0001-8884-2357 \\ bernardofmachado@gmail.com \\ Gustavo Rossi "' \\ https://orcid.org/0000-0001-7096-9966 \\ Igusfrossi@hotmail.com \\ José Maurício Arruti \\ https://orcid.org/0000-0002-7281-1158 \\ jmarruti@unicamp.br \\ I Universidade Estadual de Campinas - Campinas, SP, Brasil \\ " Universidade Estadual de Campinas - Campinas, SP, Brasil. \\ Em pós-doutoramento (bolsista Fapesp n² 2019/08713-2) \\ I' Universidade Estadual de Campinas - Campinas, SP, Brasil. \\ Em pós-doutoramento (bolsista PNPD-Capes)
}




\title{
Resumo
}

Diante da profusão de respostas intelectuais à pandemia do Sars-Cov-2, este artigo propõe sistematizar algumas das publicações realizadas pelas ciências humanas nos meses de março a junho de 2020. Inicialmente pensado como conteúdo para estudantes dos cursos de graduação, foram lidos textos presentes no volume Sopa de Wuhan, no site $n$ - 1 edições, no "Observatório do CEMI - COVID-19" (CEMI/Unicamp), no Boletim Cientistas Sociais e o Coronavírus (Anpocs), e no site antropoLÓGICAS EPIDEMICAS (UFRGS). A leitura dessa produção, marcada por textos relativamente curtos, em formatos variados, de rápida escrita e circulação, com caráter ora ensaístico, ora analítico, sugere dois principais eixos temáticos referentes 1) à problemática da escala; 2) à problemática do biopoder e dos governos. Ao fazer um recorte instantâneo das reações mais imediatas à crise, observamos perspectivas e conceitos-chave lançados pelas ciências humanas para compreensão do mundo contemporâneo.

Palavras-chave: pandemia; Covid-19; ciências sociais; antropologia.

\begin{abstract}
Due to the profusion of intellectual responses to the Sars-Cov-2 pandemic, this article systematizes some publications carried out by humanities from March to June 2020. The proposal was initially thought of as content for undergraduate students and dealt with texts present in the volume Wuhan soup, on the $n$ - 1 website, the "CEMI Observatory - COVID-19" (Unicamp), the Anpocs Bulletin, and the anthropoLÓGICAS Epidêmicas website (UFRGS). Such production is marked by relatively short texts, in varied compositions, of fast writing and circulation. Some of them have an essayistic format, and others have an analytical approach. In this article, we discuss both the content and methodological perspectives of the material. We present a transversal reading of this production, suggesting two main thematic axes regarding 1) the problem of scale; 2) the problem of biopower and governments. With this effort, we emphasize the perspectives and concepts of social science to apprehend the contemporary world.
\end{abstract}

Keywords: pandemic; Covid-19; social sciences; anthropology. 


\section{Introdução}

A palavra "infodemia" é ótima candidata a entrar nos dicionários depois do ano de 2020. O termo tem sido empregado pela Organização Mundial da Saúde (OMS) para dizer que a pandemia da Covid-19 veio acompanhada por "um excesso de informações, algumas precisas e outras não, que tornam difícil encontrar fontes e orientações confiáveis quando se precisa" (Organização Pan-Americana da Saúde, 2020). Nesse contexto, não é exagerado dizer que as próprias respostas intelectuais à Covid-19 aproximaram-se de pelo menos duas características da "infodemia": a velocidade com que novas informações surgiam e o seu compartilhamento em redes sociais e programas de mensagens instantâneas. Isso nos pareceu até certo ponto contraproducente, pois a rapidez atuava no sentido contrário do aprofundamento de um debate crítico, provocando mais ansiedade.

Este artigo é uma reação à vertigem ocasionada pela profusão de análises que, junto com o surto epidêmico, irrompeu nas ciências sociais e humanas no primeiro semestre de 2020 , ainda que de forma muito difusa em diferentes veículos - das redes sociais aos grandes jornais. Dito isso, é preciso explicitar que não se trata propriamente de uma crítica, uma vez que, no geral, as ciências humanas entraram no debate público de modo a qualificá-lo e adensá-lo. O que nos guiou, sobretudo, foi a percepção compartilhada quanto à necessidade de realizar uma reflexão sobre o que estava sendo produzido naquele contexto mais imediato de irrupção da crise sanitária.

Assim, em vez de adicionarmos mais uma análise, optamos por realizar um exercício reflexivo sobre a própria produção que se acumulava. A ideia foi sistematizar as considerações feitas no calor da hora, durante a "emergência" provocada pela pandemia, indagando: o que aborda essa produção? Como interpela a conjuntura à luz da pesquisa em ciências sociais? Quais os seus focos de observação? Por que temos gastado tanta tinta, afinal? E, por fim, como cientistas sociais, o que se comunica ao público mais ampliado? Eis algumas de nossas perguntas que, ao fim e ao cabo, trazem elas mesmas a marca do tempo de urgência das grandes crises, um tempo distinto daquele exigido pela pesquisa.

É importante notar que não se trata de um esforço panorâmico sobre toda a produção realizada em torno da pandemia até este momento em que escrevemos o artigo. Muito, inclusive, não pôde ser abarcado. Este texto - curto, 
homólogo à produção analisada e espécie de resposta às exigências acadêmicas e docentes colocadas às universidades - pretende apresentar uma leitura transversal dessa produção, com o objetivo de iluminar algumas de suas escolhas teóricas, analíticas e metodológicas. Antes, porém, de passarmos à dimensão analítica e conceitual, apresentaremos um esboço do material analisado, que foi também selecionado a partir da nossa experiência como leitores e professores interessados em trabalhar os temas suscitados pela pandemia com estudantes. Consideramos que o perfil dos textos produzidos resulta significativo para a compreensão de como as ciências humanas e, particularmente, as ciências sociais se comportaram naquele momento inicial da crise.

\section{Sobre os materiais}

Os materiais sistematizados e analisados derivam de algumas das principais iniciativas editoriais daquele momento. Sua escolha se justificou, fundamentalmente, por duas razões: 1) pela agilidade com que tais iniciativas, surgidas logo nos primeiros meses de 2020, rapidamente se transformaram em referências para a organização de reflexões qualificadas da pandemia; 2) pela diversidade intelectual, disciplinar, geográfica e institucional desses materiais, os quais, naquele momento, ofereceram uma amostra compacta, porém expressiva, das reflexões provocadas pela pandemia no âmbito das ciências sociais e humanas, tanto nacionais quanto internacionais.

Nossa seleção contempla cerca de 340 textos publicados no volume Sopa de Wuhan; na série "Pandemia Crítica", no site da n-1 edições; no "Observatório" do Centro de Estudos em Migrações Internacionais da Universidade Estadual de Campinas (CEMI/Unicamp); no boletim da Associação Nacional de Pós-Graduação e Pesquisa em Ciências Sociais (Anpocs), e no site antropoLÓGICAS EPIDÊMICAS, da Universidade Federal do Rio Grande do Sul (UFRGS). Sob uma perspectiva mais geral, tais publicações dividiram-se entre aquelas que circularam inicialmente nas redes mais diretamente ligadas às universidades e, particularmente, naquelas relacionadas às ciências sociais no Brasil, mas também iniciativas que integraram projetos editoriais de fronteiras disciplinares mais borradas, aproximando-se, em especial, da filosofia. Esta última característica aplica-se à n-1 edições e ao livro Sopa de Wuhan, como veremos. 
Quanto à n-1 edições, desde março de 2020, o site da editora transformou-se em plataforma para publicação de pensamentos surgidos sobre a pandemia. Fundada em 2011, a editora n-1 publica materiais de diversas disciplinas, como filosofia, estética, clínica, antropologia e política. A seleção dos textos divulgados sobre a pandemia seguiu essa linha editorial sob o título de "Pandemia Crítica", cujo objetivo expresso era "fazer circular cotidianamente pensamentos surgidos no calor dos acontecimentos" (n-1 edições, 2020).

Com periodicidade de divulgação diária, foram publicados 81 textos até o início de junho (muitos divulgados originalmente em outras plataformas). No que toca à autoria, houve uma presença maciça de homens: foram 49 , um deles autodenominado trans, e 26 mulheres. Além disso, nota-se o grande volume de reflexões oriundas do norte global: 22 (Europa), 7 (América do Norte) e 2 (China). O continente africano é representado por apenas um texto, de Achille Mbembe, de Camarões, ao passo que o Brasil contribuiu com 44 intervenções. Vale destacar igualmente a filiação disciplinar das assinaturas. Embora algumas pessoas se denominassem oriundas de múltiplos campos de atuação, havia uma proeminência de quem se identificava como filósofo/a, 24 no total. Em seguida, seriam 11 ensaístas, 10 antropólogos/as, 8 do universo das artes, 4 historiadores/as, 4 da psicologia/psicanálise, 3 ativistas e 13 pessoas de disciplinas diversas, como arquitetura, medicina, direito e outras.

Diante dessa grande diversidade de posições, é difícil saber para quem exatamente autores e autoras endereçaram suas reflexões. Há entrevistas, crônicas, textos com um teor ensaístico, outros de caráter mais analítico, há quem tenha sugerido propostas de ação e quem tenha feito relatos pessoais, denúncias e poesias. Apesar dos textos desafiarem categorizações e sistematizações simples, entendemos que, ainda no primeiro semestre de 2020, eles circularam com intensidade pelas redes sociais da academia brasileira e informaram o debate inicial a respeito da pandemia no país, e por isso mereceram nossa atenção.

Sobre Sopa de Wuhan, o livro é uma compilação de textos antes publicados na mídia, entre fevereiro e março de 2020, organizado por Pablo Amadeo - argentino, professor de Comunicação Social, ativista e editor da ASPO (Aislamiento Social Preventivo y Obligatorio). Em comum com a iniciativa da n-1 estão os escritos de alguns dos autores que aparecem em "Pandemia Crítica", como Giorgio Agamben, Jean-Luc Nancy, Franco “Bifo” Berardi e Paul B. Preciado. Em termos de gênero, há também aqui uma predominância de autores homens, 
um deles autoidentificado como homem trans: 12 homens e 3 mulheres. Como no projeto da n-1, parte importante dos participantes de Sopa de Wuhan têm formação na filosofia, como Judith Butler e Giorgio Agamben, embora haja também autores com outras formações, como o geógrafo David Harvey ou a psicóloga e ativista María Galindo. Apesar disso, o que marca o conjunto é o esforço para pensar o mundo contemporâneo desde uma perspectiva atenta às desigualdades e às relações de poder e comprometida com a transformação social.

Chama a atenção, ainda, os veículos nos quais os textos circularam originalmente: a maioria foi publicada em websites de coletivos ativistas e culturais, como o espanhol La Vorágine ou o italiano Antinomie; o restante foi publicado em jornais de maior circulação, como El País (Espanha). O fato de serem compilados por um professor, ativista, designer e editor argentino revela também algo das redes de comunicação internacionais que articulam ativismos, crítica social e arte. Essa característica permite adiantar o forte componente crítico das publicações, em que pese o foco na experiência da Europa e Estados Unidos, com algumas exceções.

Tanto Sopa de Wuhan como "Pandemia Crítica" refletem uma experiência do norte global. Isso se explica em parte pela própria dinâmica da pandemia, que tem origem na China e alcança Europa e Estados Unidos antes de chegar à América Latina. Ao atingir Europa e Estados Unidos, produziu-se um conhecimento que imediatamente pautou reflexões e ações na América Latina. Alguns dos autores dessas iniciativas já tinham uma produção que circulava internacionalmente, como Judith Butler, David Harvey, Slavoj Žižek, Giorgio Agamben, Paul B. Preciado, Achille Mbembe, entre outros. Ao alastrar-se, a pandemia também fez circular em velocidade viral a produção de intelectuais influentes do norte global, já conhecidos em nossos meios acadêmicos e que ofereceram uma primeira leitura para o que estaríamos por enfrentar. No caso dos países latino-americanos, esses textos emergiram posteriormente, acompanhando a própria pandemia. Apesar desse viés, Sopa de Wuhan e "Pandemia Crítica" foram as primeiras reflexões organizadas suscitadas pela pandemia a surgirem em nossas redes.

No Brasil, algumas das iniciativas mais imediatas e expressivas dos cientistas sociais do país foram veiculadas pelos boletins Cientistas Sociais e o Coronavírus e o antropoLÓGICAS EPIDÊMICAS, ambos concebidos como espaços 
de reflexão e afirmação da relevância das ciências sociais e humanas para o enfrentamento da pandemia no país.

Iniciado em 22 de março, o boletim Cientistas Sociais e o Coronavirus, fruto da iniciativa de associações científicas da área de ciências sociais e humanas e veiculado no site da Associação Nacional de Pós-graduação em Ciências Sociais, fez circular diariamente um ou dois textos curtos, com o objetivo de dar visibilidade à produção de cientistas sociais atuantes em universidades do país, num movimento de demonstração de relevância analítica e política frente aos ataques que especialmente as ciências sociais vêm sofrendo. Como reconhece o texto de balanço final escrito por Grossi, Toniol e Lozano (2020), o boletim configurou seu formato atento ao risco da infodemia pandêmica. Em vez de artigos com formatos acadêmicos tradicionais, a proposta era de ensaios limitados a mil palavras, com linguagem acessível e em diálogo com as redes sociais. Até o início de junho de 2020, a produção abarcava 51 boletins e 77 textos, muitos produzidos em coautoria, assinados por 52 homens e 52 mulheres, em sua maioria doutores/as, filiados/as às universidades do Sudeste.

O boletim abarcou os impactos da pandemia nos grupos mais vulneráveis, como é o caso das comunidades rurais, negras, quilombolas, indígenas, das pessoas em privação de liberdade e em situação de rua. A análise conjunta demonstra uma impressionante capilaridade de temas e problemas abordados sobre a pandemia desde as ciências sociais no país. Processos de saúde e doença, noções de aprimoramento corporal e salvação individual, retrocessos nas dinâmicas de trabalho, debate sobre políticas de transferência de renda, abordagens feministas que indicam as mulheres como as principais afetadas pelo isolamento social imposto, tensões entre religião e autoridade científica, sentidos de morte e reorientação de seus ritos, lugar social da infância e do envelhecimento. Muito dessa produção enfrentou textualmente as políticas de morte de Jair Bolsonaro.

Quanto ao antropoLÓGICAS EPIDÊMICAS, as primeiras publicações também surgiram em finais de março de 2020, como uma iniciativa de pesquisadores/as e docentes das áreas da antropologia, psicologia e saúde coletiva, vinculados/as, sobretudo, à Universidade Federal do Rio Grande do Sul (UFRGS). Segundo os/as organizadores/as, tratava-se de "exercitar/incentivar a imaginação (auto)etnográfica, sociológica e política sobre a pandemia”, proporcionando, assim, um espaço de "debate qualificado" sobre as múltiplas implicações da pandemia. 
Entre finais de março e a primeira semana de junho de 2020, o site publicou 103 textos (excluídas as produções audiovisuais e artísticas), de 102 autores/as diferentes, num ritmo médio de 50 escritos por mês. O antropoLÓGICAS funcionou como um espaço divulgador de conteúdo fundamentalmente associado ao universo acadêmico brasileiro, o qual foi responsável por 92 das autorias analisadas. Dos 102 autores/as, 57 são do gênero masculino e 45 são do gênero feminino (duas delas autodenominadas mulheres trans). Considerando unicamente os/as autores/as nacionais que declararam suas instituições de vínculo ou formação, é significativo destacar que a maioria quase absoluta provinha de universidades públicas brasileiras. Vale destacar o fato de que, do total dos textos analisados, apenas pouco mais de metade eram contribuições originais, sendo o restante textos já publicados em outras mídias, jornais ou boletins, sobretudo, o da Anpocs, potencializando, assim, a circulação e a ressonância de análises que, de outra forma, não encontraríamos de modo centralizado e organizado.

Condizente com o perfil disciplinar dos/as organizadores/as, o antropoLÓGICAS reuniu autores/as majoritariamente das ciências sociais e da psicologia, mas, sobretudo, da antropologia. Antropólogos/as assinaram mais de um terço das publicações. A diversidade temática respondeu, de um lado, à temporalidade social e política da gestão da pandemia no Brasil e, de outro, às linhas de trabalhos prévios dos/as autores/as, que se viram instados/as a repensar, interromper ou reorientar seus temas de investigação à luz das medidas de isolamento e das mortes provocadas pela pandemia. Não parece aleatória a expressiva presença de análises que buscaram lidar com as múltiplas escalas e dimensões da bio/necropolítica, articuladas ainda a uma forte ênfase a cenários e sujeitos que, no Brasil, estão sendo mais particularmente afetados pela combinação entre desigualdades, autoritarismo, precarização de direitos e ausência de políticas públicas adequadas ao combate da pandemia.

Já o "Observatório do CEMI - COVID 19" publicou um volumoso conjunto de ensaios sobre o cotidiano da pandemia em países tão distintos quanto os EUA, Irã e Equador. Com ênfase na abordagem etnográfica, os textos cobriram um amplo leque de gêneros: do relato pessoal ao estilo diário íntimo do isolamento social, incluindo até uma reflexão sociofilosófica sobre o pós-isolamento. Entre esses extremos, couberam os relatos de antropólogos que foram surpreendidos 
pela pandemia em pleno trabalho de campo, da antropóloga presa em casa, até análises de conjuntura política e textos que se aproximam dos relatórios de organizações de direitos humanos. O perfil dos autores reunidos também foi muito diverso, indo do ex-presidente da Associação Europeia de Antropologia até à estudante indígena recém-ingressada na Unicamp, passando por muitos jovens antropólogos.

Entre 26 de março e o final do mês de junho de 2020, o "Observatório" reuniu 63 textos, sobre 33 países, distribuídos por África (13 países), Europa (9), Caribe (7), Oriente Médio (2), América Latina (5), além de Estados Unidos e China. Os países mais representados, além do Brasil (17 relatos), foram Moçambique (10) e Haiti (5), o que reflete a composição dos pesquisadores do CEMI e os interesses e conexões do organizador e editor da iniciativa. Vale destacar que o número de relatos sobre o Brasil, ainda que regionalmente concentrados (sete sobre o estado de São Paulo e três sobre a cidade do Rio de Janeiro), foi relativamente pequeno em relação às outras iniciativas vinculadas a centros de pesquisa nacionais, apontando para um lugar específico na divisão institucional do trabalho na análise da pandemia.

A coleção deu acesso, assim, a reflexões sobre uma grande diversidade de situações cotidianas, afastadas do centro da produção global. Mas, ao mesmo tempo, nos permitiu perceber a emergência de alguns padrões, decorrentes dos temas que foram abordados diretamente ou que surgiram de forma lateral, mas constante. Os textos evidenciam, por exemplo, os efeitos diferenciados da política do isolamento social que, adotada de forma imediata e organizada em muitos lugares, parece não fazer sentido em determinadas situações. O conjunto variado das contribuições oferece uma perspectiva crítica sobre a atuação dos Estados nacionais, assim como sobre a implementação de uma política geral de isolamento social, em confronto com as formas de organização socioeconômica vinculadas a tradições e práticas culturais, a situação dos imigrantes, dos que trabalham na informalidade, daqueles que atuam em setores considerados essenciais, entre outras.

Nas próximas seções deste artigo, sugerimos dois principais eixos temáticos que parecem aglutinar a produção lida. São eles: 1) a problemática da escala; 2) a problemática do biopoder e dos governos. Consideramos que eles nos permitem observar escolhas teóricas, analíticas e metodológicas do material observado. 


\section{Antropologia da pandemia}

\section{Escalas e perspectivas}

O primeiro ponto de destaque nessa produção intelectual diz respeito às escalas de análise. Enquanto alguns textos procuraram dar conta de uma suposta experiência global do fenômeno - tendo como parâmetro uma "humanidade" universal -, outros se empenharam em destacar as diferenças e esmiuçar os enfrentamentos locais.

Quanto à primeira vertente, notamos em muitos textos um esforço em definir, em termos universais, o que é o vírus e o que faz o vírus. Por exemplo, Jérome Bachet destacou que a Covid-19 é uma doença do Antropoceno, resultado da exploração agropecuária e do capitalismo. Segundo Bachet (2020, grifo nosso), "o coronavírus chegou para acionar o sinal de alarme e frear o trem louco de uma civilização que corria em direção à destruição em massa da vida". Nessas formulações, o Sars-Cov-2 agiria em função da humanidade - servindo a algum interesse ou problema humano. Ele não teria uma agência per se, mas sim uma agência condicionada ao universo humano. Esse tipo de análise está presente sobretudo no site da n-1 e em Sopa de Wuhan, em ensaios como os de Žižek (2020) ou de Berardi (2020).

Tal conjunto de textos oferece explicações mais sistêmicas, com foco no capitalismo global como origem das crises contemporâneas. São elaborações que frequentemente remetem às experiências históricas da classe trabalhadora ou da classe média assalariada europeia como sujeitos paradigmáticos de suas análises. Os textos, em geral, propõem uma crítica aos modos de produção e de consumo capitalistas, concebendo o vírus como uma oportunidade para repensar o "sistema". São pontos de vista que tomam experiências históricas e sociais específicas como passíveis de serem universalizadas como explicação global da pandemia.

É possível identificar em algumas abordagens um esforço para nomear a experiência do vírus e, com isso, pacificar, um pouco, as incertezas geradas por essa experiência difícil. Nessa seara, há as propostas com um franco tom otimista, como as do filósofo Jean-Luc Nancy (2020), que defende a ideia de que "o vírus nos comuniza", na medida em que "nos coloca em pé de igualdade e nos junta na necessidade de enfrentar o conjunto". 
Esses textos se abstêm de uma reflexão mais voltada às formas localizadas pelas quais a pandemia se apresenta à vida cotidiana dos sujeitos. Jean Segata (2020), interessado em pensar como a antropologia pode atuar nesses eventos, destaca um duplo caráter das perspectivas analíticas de eventos globais. Segundo o autor, "números, casos, estatísticas ou prevalências têm rosto, trajetória e biografia [...]. Então, a pandemia precisa ser considerada como uma experiência vivida nos corpos e nas sensibilidades coletivas" (Segata, 2020). Apoiado na leitura de Anna Tsing (2005), ele enfatiza ainda que se a Covid-19é uma doença em escala global, isso não faz dela um fenômeno universal, sendo necessário observar de forma situada os seus efeitos.

Assim, a segunda vertente se dedica à mediação entre as dinâmicas globais do capitalismo e os modos como o vírus afeta desigualmente as populações. Aqui, mais do que um sujeito trabalhador universal, a análise é conduzida pela preocupação com as pessoas que estão na linha de frente da epidemia. Como afirma Harvey (2020), a Covid-19 é uma pandemia de classe, gênero e raça; ou, segundo Butler (2020), se todos em princípio somos vulneráveis ao vírus, a desigualdade social assegura que o vírus discrimine as vidas mais e menos expostas ao risco e à letalidade. Tais análises, ao tomarem as desigualdades como foco, permitiram também a crítica social a aspectos tão amplos como o modelo de exploração capitalista da natureza e o modelo de negócios aplicado à gestão da saúde, por exemplo.

Tal esforço analítico indaga como as diferenças e desigualdades impactam as formas de experimentar a pandemia em contextos situados. Esse é o caso do "Observatório do CEMI - COVID-19" e do projeto antropoLÓGICAS EPIDÊMICAS, cujo foco está nos desafios evidenciados, provocados ou mesmo agravados pela crise pandêmica. No caso brasileiro, a conjuntura política nacional teve um impacto, direto ou indireto, situando o presidente da república, Jair Bolsonaro, como o principal aliado político das mortes causadas pelo vírus no território nacional (ver, por exemplo, Torelly, 2020).

As escalas analíticas, desse modo, atravessaram as análises produzidas sobre o fenômeno pandêmico, indicando aspectos das políticas acadêmicas do norte e sul global e interesses disciplinares variados. Sobre o tema, acreditamos ser necessário enfrentar uma discussão aprofundada dos modelos epistêmicos - suas rentabilidades e limites. 


\section{O governo dos corpos e a gestão das mortes}

O segundo aspecto a ser destacado é o emprego privilegiado das noções de biopoder, biopolítica e necropolítica nos textos considerados. Dessa maneira, decidimos perseguir alguns de seus usos e refletir sobre seus rendimentos epistêmicos.

O biopoder, tal como definido por Michel Foucault (2005), ao tomar a forma de discursos, rotinas institucionais, enunciados científicos e práticas estatais, instala uma lógica de guerra permanente contra sujeitos transformados em inimigos internos à própria sociedade, em ameaça à saúde das populações e à reprodução desse seu patrimônio biológico. Ao articular poder, vida e morte, corpo e biologia, essa chave teórica parece ter se tornado incontornável nas análises sobre a vida social da Covid-19.

Preciado (2020), por exemplo, mobilizou a noção de biopolítica para lembrar que não há política que não seja uma política dos corpos. Segundo o autor, as epidemias materializam no corpo individual as obsessões que dominam a gestão política da vida e da morte das populações. Esse evento de escala global acionou uma memória coletiva de outras infecções. Diversas avaliações recorreram à epidemia de HIV/Aids e ao descaso dos governos diante dos chamados "grupos de risco": homossexuais, viciados e prostitutas (Coitinho Filho, 2020; Pinheiro, 2020; Saggese, 2020). Preciado (2020), contudo, lembra-nos de que apesar das fantasias de soberania sexual masculina, as epidemias como o HIV/Aids e a sífilis não foram mitigadas pelo controle e pela marginalização de determinadas populações, mas pelo conhecimento, pela distribuição ampla e global de medicamentos e pela conquista de direitos para mulheres e LGBTI+.

A noção de necropolítica de Achille Mbembe (2016) também ofereceu uma importante chave para pensar formas de exercício do poder cujos pressupostos se baseiam não no reconhecimento, mas na radical negação da igualdade de certas populações. Há a indicação de como os governos colocaram a própria razão a serviço da exploração, da instrumentalização e da eliminação sistemática de determinados corpos. Como observa Granada (2020), "se deixa morrer, ou se mata, os mais vulneráveis".

A partir dessas chaves de entendimento, nota-se o esforço para revelar a extensão dos efeitos do neoliberalismo sobre o tecido social tanto de países que já experimentaram um Estado de bem-estar social quanto daqueles que 
nunca conseguiram chegar a ele (Cesarino, 2020; Silveira, 2020). Muitos relatos estão marcados pela evidência do abandono da população por parte do Estado (Schuch; Furtado; Sarmento, 2020), assim como se questiona o que se tornou, no Brasil, uma antinomia entre "vida" e "economia" (Neiburg, 2020). A presença do Estado - na sua versão violenta ou precarizadora, sustentada numa racionalidade que substitui a cidadania ou o bem-estar social por uma análise de custo-benefício - está relacionada a outros dois temas recorrentes.

O primeiro tema é o das ambiguidades da política do isolamento social que, adotada de forma imediata e organizada em muitos lugares, parece não responder apenas às orientações da OMS, mas também a outras razões. Em alguns lugares, por resumir tudo que o Estado tem a oferecer diante da situação (Paño, 2020). Em outros, por responder a uma lógica de responsabilização do estrangeiro, culpabilização das vítimas da doença e atualização de políticas xenofóbicas antigas ou recentes (Basch, 2020; Tsambe, 2020a, 2020b; Wane, 2020). Finalmente, em quase todos os lugares, por ampliar as desigualdades sociais, de gênero e étnico-raciais, na medida em que as reforça sob uma nova diferença, entre os que podem e os que não podem realizar o isolamento físico (Lima; Barros, 2020). Nesse caso, há pessoas impedidas em função de sua situação socioeconômica vinculada a tradições e práticas culturais (Bulamah, 2020; Capiberibe, 2020; Cichocki, 2020; Loera, 2020); há imigrantes, ilegais e/ou informais (Frangella, 2020); há pessoas confinadas em cárceres superlotados (Mallart et al., 2020); há também profissionais em setores considerados essenciais (Matos, 2020). Como nota Butler (2020, p. 62, tradução nossa): "A desigualdade social e econômica garantirá a discriminação do vírus."

O segundo tema é o do oportunismo governamental diante da pandemia. Novas levas de ajuda internacional são apontadas como oportunidades econômicas para as elites locais (Montinard, 2020; Telibećirović, 2020). A política de isolamento e controle de informação pode se transformar na extensão do controle estatal sobre seus cidadãos e seus meios de comunicação (Han, 2020; Preciado, 2020; Ribeiro, 2020). A discricionariedade do Estado em determinar quais são os serviços essenciais (e, portanto, quem está sob risco de contágio) é apontada como extensão do poder de setores econômicos que permanecem acima da justiça e do bom senso, como a mineração (Lopo, 2020) e o agronegócio (Lima, 2020). 


\section{Escalas da necropolítica e os horizontes da antropologia}

Como afirmamos no início do texto, nossa pretensão não foi realizar um panorama da produção em torno da pandemia, mas oferecer uma leitura das reações imediatas das ciências sociais e humanas à crise. Como Preciado (2020), nos colocamos nessa empreitada na posição de aprender com o vírus e sobre o vírus. Nos perguntamos a respeito do que essa infecção revela acerca das relações sociais e das formas situadas de compreensão do mundo. A multiplicidade de contribuições ofereceu escalas, conceitos e narrativas a respeito de como as sociedades vão encontrando seus próprios caminhos diante do caos que lhes foi imposto, acionando críticas sistêmicas, memórias coletivas, mobilizando saberes tradicionais ou articulando redes de apoio mútuo e solidário.

"Em um mundo cada vez mais dominado pela assombração de seu próprio fim" (Mbembe, 2020), muitos dos textos nos chamaram a atenção para a urgência do que se deve levar em conta nas políticas públicas de enfrentamento, especialmente em contextos de extrema precariedade de direitos e acesso a serviços públicos e de saúde, uma vez que determinados grupos e setores sociais estão, mais do que outros, expostos ao risco - e não somente em termos epidemiológicos. Por exemplo, mulheres para as quais o isolamento social representa, por vezes, risco de violência doméstica (Lins, 2020) e sobrecarga dos cuidados domésticos e familiares. Por fim, as vulnerabilidades de pessoas em situação de rua ou moradoras de área com infraestrutura insuficiente evidenciam a necessidade de políticas capazes de ir além das soluções consideradas básicas, como a orientação de lavar as mãos e a reclusão em um lar.

Com isso em mente, duas observações orientam nossas conclusões. A primeira é que uma forma de controlar a vertigem ocasionada pela "infodemia" passa por reconhecer que as análises disponíveis dizem respeito a um fenômeno ou agente múltiplo, controverso, sobre o qual se debatem incessantemente os sentidos, as causas, os efeitos, os seus limites e suas formas; sobre o qual se debate também não exatamente a sua agência, mas os seus agenciamentos por outros agentes, em uma cadeia de implicações. A situação é excepcional também do ponto de vista intelectual, na medida em que tantos olhares buscam, de modos muito distintos mas simultâneos, um mesmo ponto, que se move, que é mutante e que cruza diferentes escalas. 
A segunda é sugerir como ambas as características destacadas na produção disponível - a oscilação entre as escalas e o privilégio às questões em torno da biopolítica - podem estar articuladas entre si. Se, como aponta Revel (1998), o jogo de escalas parece mais interessante do que tomar partido definitivo por uma delas, a biopolítica parece ter ganhado destaque justamente pela sua capacidade de oferecer perguntas (não exatamente respostas) operáveis em diferentes escalas. $\mathrm{E}$ a sua reapropriação pós-colonial, sob a forma da necropolítica, parece ter tido um papel importante na sua abertura a novos contextos e injunções, inspirando muitas das microdescrições a que tivemos acesso, quando não teoricamente, ao menos tematicamente.

De certa forma, é nessa chave, por exemplo, que parte importante da produção nacional enfrentou textualmente as políticas do presidente do Brasil, seu ataque contínuo à ciência, o descaso em relação a direitos sociais e trabalhistas, a sua sugestão de implementação de isolamento vertical num país de cidadania vertical (Campos, 2020), bem como sua postura de completo desrespeito aos mortos e familiares, cujos rituais funerários têm sido completamente alterados (Irrazábal, Olmos Álvarez, 2020; Rial, 2020; Silva, 2020). Tendo o vírus como aliado, "a morte de muitos é a política de saúde do governo Bolsonaro" (Gherman; Almeida, 2020).]

Diante do cenário aberto, de desafios inéditos e dilemas até então inconcebíveis, é importante considerar que nossos quadros analíticos, conceituais e metodológicos foram forjados em contextos distintos deste que atravessamos. Vale perguntar o quanto eles podem ser adaptáveis ou transpostos para um mundo passível de ser adoentado, e, tão importante quanto, vale perscrutar como as pessoas com as quais interagimos estão agindo e imaginando esse mesmo mundo. Nesse sentido, o breve sobrevoo aqui realizado nos parece importante para indicar a necessidade de uma revisão epistêmica que discuta se o que fazemos agora é capaz de responder aos desafios de um mundo ou de uma normalidade definitivamente alterados pela pandemia global. 


\section{Referências}

BACHET, J. Covid-19: o século XXI começa agora. In: N-1 EDIÇÕES. Pandemia crítica (17). São Paulo: n-1 edições, 2020. Disponível em: https://www.n-1edicoes.org/textos/50. Acesso em: 30 ago. 2020.

BASCH, G. Pandemia, autocracia e memória em Budapest. In: CEMI. Observatório do CEMI COVID-19, n. 4. Campinas: CEMI, 30 mar. 2020. Disponível em: https:// cemiunicamp.com.br/observatorio-no-4/. Acesso em: 30 ago. 2020.

BERARDI, F. B. Crônicas da psicodeflação. In: N-1 EDIÇÕES. Pandemia crítica (12). São Paulo: n-1 edições, 2020. Disponível em: https://www.n-1edicoes.org/textos/31. Acesso em: 30 ago. 2020.

BULAMAH, R. Pandemia e estagnação no Haiti. In: CEMI. Observatório do CEMI COVID-19, n. 6. Campinas: CEMI, 1 abr. 2020. Disponível em: https://cemiunicamp. com.br/observatorio-no-6/. Acesso em: 30 ago. 2020.

BUTLER, J. El capitalismo tiene sus límites. In: AMADEO, P. (ed.). Sopa de Wuhan. La Plata: Editorial ASPO, 2020. p. 59-65.

CAMPOS, M. da S. A cidadania vertical no Brasil: o caso do coronavírus. Boletim Cientistas Sociais e o Coronavírus, São Paulo, n. 21, 15 abr. 2020. Disponível em: http:// anpocs.org/index.php/publicacoes-sp-2056165036/boletim-cientistas-sociais/2334-boletim-n-21-a-cidadania-vertical-no-brasil-o-caso-do-coronavirus. Acesso em: 30 ago. 2020.

CAPIBERIBE, A. Covid-19: um velho-novo conhecido dos indígenas. Boletim Cientistas Sociais e o Coronavírus, São Paulo, n. 18, 10 abr. 2020. 18. Disponível em: https:// anpocs.org/index.php/publicacoes-sp-2056165036/boletim-cientistas-sociais/2331-boletim-n-18-covid-19-um-novo-velho-conhecido-dos-indigenas. Acesso em: 30 ago. 2020.

CESARINO, L. Coronavírus como força de mercado e o fim da sociedade. In: GRUNVALD, V. et al. (ed.). antropoLÓGICAS EPIDÊMICAS, [s. l.], 22 abr. 2020. Disponível em: https://www.antropologicas-epidemicas.com.br/post/coronav\%C3\%ADrus-como-for\%C3\%A7a-de-mercado-e-o-fim-da-sociedade. Acesso em: 30 ago. 2020.

CICHOCKI, P. MaChinese sazatheka. Chinese did it again. Chasing away the hurricane from Malawi. In: CEMI. Observatório do CEMI COVID-19, n. 36. Campinas: CEMI, 29 abr. 2020. Disponível em: https://cemiunicamp.com.br/observatorio-no-36/. Acesso em: 30 ago. 2020. 
COITINHO FILHO, R. A. A (re)apropriaçao da categoria "grupos de risco" - da Aids ao Covid - e a permanência do estigma sobre sujeitos em contextos pandêmicos. Boletim Cientistas Sociais e o Coronavírus, São Paulo, n. 39, 13 maio 2020. Disponível em: https://anpocs.org/index.php/publicacoes-sp-2056165036/boletim-cientistas-sociais/2353-boletim-n-39-cientistas-sociais-e-o-coronavirus. Acesso em: 30 ago. 2020.

FOUCAULT, M. Em defesa da sociedade: curso no Collège de France (1975-1976). São Paulo: Martins Fontes, 2005.

FRANGELLA, S. Lisboa na quarentena, novas sensações e problemas antigos. In: CEMI. Observatório do CEMI COVID-19, n. 26. Campinas: CEMI, 20 abr. 2020. Disponível em: https://cemiunicamp.com.br/observatorio-no-26/. Acesso em: 30 ago. 2020.

GHERMAN, M.; ALMEIDA, R. Bolsonaro: o vírus como aliado. Estado da Arte, São Paulo, 12 jul. 2020. Disponível em: https://estadodaarte.estadao.com.br/bolsonaro-virus-aliado-bnfb-gherman-almeida/. Acesso em: 30 ago. 2020.

GRANADA, D. A gestão da pandemia do coronavírus. In: GRUNVALD, V. et al. (ed.). antropoLÓGICAS EPIDÊMICAS, [s. l.], 20 maio 2020. Disponível em: https:// www.antropologicas-epidemicas.com.br/post/a-gest\%C3\%A3o-da-pandemia-do-coronav\%C3\%ADrus-covid-19-no-brasil-e-a-necropol\%C3\%ADtica-1. Acesso em: 30 ago. 2020.

GROSSI, M. P.; TONIOL, R.; LOZANO, M. Finalizando a primeira série do Boletim Cientistas Sociais e Coronavírus: um balanço inicial. Boletim Cientistas Sociais e o Coronavírus, São Paulo, n. 86, 17 jul. 2020. Disponível em: https://anpocs.org/index. $\mathrm{php} /$ publicacoes-sp-2056165036/boletim-cientistas-sociais/2418-boletim-cientistas-sociais-n-86. Acesso em: 30 ago. 2020.

HAN, B.-C. La emergencia viral y el mundo de mañana. In: AMADEO, P. (ed.). Sopa de Wuhan. La Plata: Editorial ASPO, 2020. p. 97-112.

HARVEY, D. Política anticapitalista en tiempos de coronavirus. In: AMADEO, P. (ed.). Sopa de Wuhan. La Plata: Editorial ASPO, 2020. p. 79-96.

IRRAZÁBAL, G.; OLMOS ÁLVAREZ, A. L. ¿Como se gestionan la muerte y el duelo en situaciones de pandemia?. Boletim Cientistas Sociais e o Coronavírus, São Paulo, n. 25, 22 abr. 2020. Disponível em: https://anpocs.org/index.php/publicacoes-sp-2056165036/boletim-cientistas-sociais/2339-boletim-n-25-cientistas-sociais-e-o-coronavirus. Acesso em: 30 ago. 2020. 
LIMA, L. Se esperarmos o agronegócio, morreremos de fome: população em quarentena quer alimentos, não commodities. Boletim Cientistas Sociais e o Coronavírus, São Paulo, n. 27, 24 abr. 2020. Disponível em: https://anpocs.org/index.php/publicacoes-sp-2056165036/boletim-cientistas-sociais/2341-boletim-n-27-cientistas-sociais-e-o-coronavirus. Acesso em: 30 ago. 2020.

LIMA, R. W.; BARROS, J. "Isto é uma guerra": Cabo Verde e as medidas sociais de suporte à contenção do Covid-19. In: CEMI. Observatório do CEMI COVID-19, n. 35. Campinas: CEMI, 29 abr. 2020. Disponível em: https://cemiunicamp.com.br/observatorio-no-35/. Acesso em: 30 ago. 2020.

LINS, B. A. Mulheres, violência doméstica e Covid-19: o que a tecnologia tem a ver com isso?. In: GRUNVALD, V. et al. (ed.). antropoLÓGICAS EPIDÊMICAS, [s. l.], 13 abr. 2020. Disponível em: https://www.antropologicas-epidemicas.com.br/post/mulheres-viol\%C3\%AAncia-dom\%C3\%A9stica-e-a-covid-19-o-que-a-tecnologia-tem-a-ver-com-isso. Acesso em: 30 ago. 2020.

LOERA, N. As populações do campo e o coronavírus. Boletim Cientistas Sociais e o Coronavírus, São Paulo, n. 13, 4 abr. 2020. Disponível em: https://anpocs.org/index. php/publicacoes-sp-2056165036/boletim-cientistas-sociais/2324-boletim-n-13-as-populacoes-do-campo-e-o-coronavirus. Acesso em: 30 ago. 2020.

LOPO, R. Covid e mineração: a crise como contexto e o lucro como necessidade. Boletim Cientistas Sociais e o Coronavírus, São Paulo, n. 28, 27 abr. 2020. Disponível em: https://anpocs.org/index.php/publicacoes-sp-2056165036/boletim-cientistas-sociais/2342-boletim-n-28-cientistas-sociais-e-o-coronavirus. Acesso em: 30 ago. 2020.

MALLART, F. et al. O massacre do coronavírus. Boletim Cientistas Sociais e o Coronavírus, São Paulo, n. 24, 20 abr. 2020. Disponível em: https://anpocs.org/index.php/ publicacoes-sp-2056165036/boletim-cientistas-sociais/2338-boletim-n-24-o-massacre-do-coronavirus. Acesso em: 30 ago. 2020.

MATOS, M. Pandemia Covid-19 e as mulheres. Boletim Cientistas Sociais e o Coronavírus, São Paulo, n. 11, 2 abr. 2020. Disponível em: https://anpocs.org/index.php/ publicacoes-sp-2056165036/boletim-cientistas-sociais/2322-boletim-n-11-pandemia-covid-19-e-as-mulheres. Acesso em: 30 ago. 2020.

MBEMBE, A. Necropolítica. Arte \& Ensaios, Rio de Janeiro, n. 32, p. 123-151, dez. 2016.

MBEMBE, A. O direito universal à respiração. In: N-1 EDIÇÕES. Pandemia crítica (20). São Paulo: n-1 edições, 2020. Disponível em: https://www.n-1edicoes.org/textos/53. Acesso em: 30 ago. 2020. 
MONTINARD, M. Son lari a sobre a epidemia do Covid-19. In: CEMI. Observatório do CEMI COVID-19, n. 32. Campinas: CEMI, 19 abr. 2020. Disponível em: https:// cemiunicamp.com.br/observatorio-no-32/. Acesso em: 30 ago. 2020.

N-1 EDIÇÕES. Pandemia crítica. São Paulo: n-1 edições, 2020. Disponível em: https://www.n-1edicoes.org/textos. Acesso em: 30 ago. 2020.

NANCY, J. Comunovírus. In: N-1 EDIÇÕES. Pandemia crítica (8). São Paulo: n-1 edições, 2020. Disponível em: https://www.n-ledicoes.org/textos/27. Acesso em: 30 ago. 2020.

NEIBURG, F. Vidas, economias e emergências. Boletim Cientistas Sociais e o Coronavírus, São Paulo, n. 22, 16 abr. 2020. Disponível em: https://anpocs.org/index.php/ publicacoes-sp-2056165036/boletim-cientistas-sociais/2335-boletim-n-22-vidas-economia-e-emergencia. Acesso em: 30 ago. 2020.

ORGANIZAÇÃO PAN-AMERICANA DA SAÚDE. Entenda a infodemia e a desinformação na luta contra a COVID-19. [S. l.]: Opas, 2020. (Página informativa, n. 5). Disponível em: https://iris.paho.org/bitstream/handle/10665.2/52054/Factsheet-Infodemic_ por.pdf?. Acesso em: 30 ago. 2020.

PAÑO, P. Día 48, desde los Andes, lejos de la costa. In: CEMI. Observatório do CEMI COVID-19, n. 37. Campinas: CEMI, 1 maio 2020. Disponível em: https://cemiunicamp.com.br/observatorio-no-37/. Acesso em: 30 ago. 2020.

PINHEIRO, R. C. Notas sobre "grupos de risco". In: GRUNVALD, V. et al. (ed.). antropoLÓGICAS EPIDEMICAS, [s. l.], 16 maio 2020. Disponível em: https://www. antropologicas-epidemicas.com.br/post/notas-sobre-grupos-de-risco-em-tempos-de-coronav\%C3\%ADrus. Acesso em: 30 ago. 2020.

PRECIADO, P. Aprendiendo del virus. In: AMADEO, P. (ed.). Sopa de Wuhan. La Plata: Editorial ASPO, 2020. p. 163-185.

REVEL, J. (org.). Jogos de escala: a experiência da microanálise. Rio de Janeiro: Editora Fundação Getúlio Vargas, 1998.

RIAL, C. Mortes belas, mortes boas, mortes malignas e a Covid-19. Boletim Cientistas Sociais e o Coronavirus, São Paulo, n. 20, 14 abr. 2020. Disponível em https://anpocs.org/ index.php/publicacoes-sp-2056165036/boletim-cientistas-sociais/2333-boletim-n-20-mortes-belas-mortes-boas-mortes-malignas-e-a-covid-19. Acesso em: 30 ago. 2020.

RIBEIRO, G. L. Medo global. Boletim Cientistas Sociais e o Coronavírus, São Paulo, n. 5, 26 mar. 2020. Disponível em: http://www.anpocs.com/index.php/ciencias-sociais/ destaques/2311-boletim-n-3-as-ciencias-sociais-e-a-saude-coletiva-frente-a-atual-epidemia-de-ignorancia-irresponsabilidade-e-ma-fe-3Medo. Acesso em: 30 ago. 2020. 
SAGGESE, G. S. R. Covid-19 e a população de travestis e transexuais: reflexões iniciais. In: GRUNVALD, V. et al. (ed.). antropoLÓGICAS EPIDÊMICAS, [s. l.], 19 abr. 2020. Disponível em: https://www.antropologicas-epidemicas.com.br/post/covid-19-e-a-popula\%C3\%A7\%C3\%A3o-de-travestis-e-transexuais-reflex\%C3\%B5es-iniciais. Acesso em: 30 ago. 2020.

SCHUCH, P.; FURTADO, C.; SARMENTO, C. S. População de rua, coronavírus e necropolítica. In: GRUNVALD, V. et al. (ed.). antropoLÓGICAS EPIDÊMICAS, [s. l.], 4 abr. 2020. Disponível em: https://www.antropologicas-epidemicas.com.br/post/ popula\%C3\%A7\%C3\%A3o-de-rua-coronav\%C3\%ADrus-e-necropol\%C3\%ADtica. Acesso em: 30 ago. 2020.

SEGATA, J. Covid-19: escalas da pandemia e escalas da antropologia. Boletim Cientistas Sociais e o Coronavírus, São Paulo, n. 2, 23 mar. 2020. Disponível em: https:// anpocs.org/index.php/publicacoes-sp-2056165036/boletim-cientistas-sociais/2307-boletim-n-1-cientistas-sociais-o-o-coronavirus-2. Acesso em: 30 ago. 2020.

SILVA, A. V. da. Velório em tempos de Covid-19. Boletim Cientistas Sociais e o Coronavírus, São Paulo, n. 25, 22 abr. 2020. Disponível em: https://anpocs.org/index.php/ publicacoes-sp-2056165036/boletim-cientistas-sociais/2339-boletim-n-25-cientistas-sociais-e-o-coronavirus. Acesso em: 30 ago. 2020.

SILVEIRA, F. Mandetta e os necroempreendedores. In: GRUNVALD, V. et al. (ed.). antropoLÓGICAS EPIDÊMICAS, [s. l.], 10 abr. 2020. Disponível em: https://www.antropologicas-epidemicas.com.br/post/mandetta-e-os-necroempreendedores. Acesso em: 30 ago. 2020.

TELIBEĆIROVIĆ, A. International isolation and its reflection in Bosnia. In: CEMI. Observatório do CEMI COVID-19, n. 33. Campinas: CEMI, 26 abr. 2020. Disponível em: https://cemiunicamp.com.br/observatorio-no-33/. Acesso em: 30 ago. 2020.

TORELLY, G. Bolsonaro e as inesperadas virtudes do camaleão. In: GRUNVALD, V. et al. (ed.). antropoLÓGICAS EPIDÊMICAS, [s. l.], 25 abr. 2020. Disponível em: https://www. antropologicas-epidemicas.com.br/post/bolsonaro-e-as-inesperadas-virtudes-do-camale\%C3\%A3o. Acesso em: 30 ago. 2020.

TSAMBE, Z. "Hiva nimphela ovirela elapo": outra forma de distanciamento social contra o Coronavírus à moda makua em Montepuez, Norte de Moçambique. In: CEMI. Observatório do CEMI COVID-19, n. 2. Campinas: CEMI, 29 mar. 2020a. Disponível em: https://cemiunicamp.com.br/observatorio-no-2/. Acesso em: 30 ago. 2020. 
TSAMBE, Z. “Temos o direito a ser iguais quando a diferença nos inferioriza; e ser diferentes quando a igualdade nos descaracteriza": desigualdade e exclusão aos estrangeiros em tempos de Coronavírus na fronteira entre o Malawi e Moçambique. In: CEMI. Observatório do CEMI COVID-19, n. 30. Campinas: CEMI, 22 abr. 2020b. Disponível em: https://cemiunicamp.com.br/observatorio-no-30/. Acesso em: 30 ago. 2020.

TSING, A. Friction: an ethnography of global connection. Princeton: Princeton University Press, 2005.

WANE, M. "Fazer mais como? Se problema estamos com ele...": o coronavírus em Moçambique. In: CEMI. Observatório do CEMI COVID-19, n. 1. Campinas: CEMI, 28 mar. 2020. Disponível em: https://cemiunicamp.com.br/observatorio-no-1/. Acesso em: 30 ago. 2020.

ŽIŽEK, S. El coronavirus es un golpe al capitalismo a lo Kill Bill. In: AMADEO, P. (ed.). Sopa de Wuhan. La Plata: Editorial ASPO, 2020. p. 21-28.

Recebido: 31/08/2020 Aceito:20/01/2021 | Received:8/31/2020 Accepted:1/20/2021 